Лисин Даниил Вадимович

аспирант кафедры истории и теории социологии Московского государственного университета им. М.В. Ломоносова

\section{ОСОБЕННОСТИ РЕПРЕЗЕНТАЦИИ КЛАССОВОГО КОНФЛИКТА В СОВРЕМЕННОЙ ЗАПАДНОЙ МАССОВОЙ КУЛЬТУРЕ НА ПРИМЕРЕ ТЕЛЕСЕРИАЛА «THЕ SIMPSONS»}

\section{Аннотация:}

В статье предпринята попытка проанализировать особенности отображения классовой структуры и классового конфликта в произведениях современной западной массовой культуры. Наиболее успешные из подобных культурных продуктов популярны практически во всем мире и влияют на установки и представления людей далеко за границами локальных сообществ. При этом мы можем говорить об отсутствии комплексного понимания того, как именно классы вообще и классовый конфликт в частности представлены в продуктах за падной массовой культуры. В рамках исследования, используя дискурс-анализ, анализируется американский мультсериал "The Simpsons» на предмет особенностей репрезентации классового конфликта. Результаты исследования свидетельствуют о том, что классовая поляризация в американском обществе, представленном в мультсериале, действительно присутствует, однако низ кий уровень классовой самочдентификации среди представителей эксплуатируемого класса и отсутствие институтов, способствующих артикуляции классовых интересов, приводят к тому, что классовый конфликт, даже имея значительный потенциал, не реализуется в своей актуальной форме, не выражается в непосредственных действиях и политических актах как нормативного так и контрнормативного порядка. При этом происходит значительная трансформация самих классов, которые уже серьезно отличаются от того классического понимания, которое ассоциируется с эпохой индустриального капитализма. Меняются не только границы классов, но и те социальные условия и фреймы, которые участвуют в форми ровании классовой идентичности в современном западном обществе.

Ключевые слова

социальная структура, социальные классы, классовый конфликт, массовая культура, популярная культура, исследования в области кино и мульти пликации.
Lisin Daniil Vadimovich

PhD Student, History and Theory of Sociology Department,

Lomonosov Moscow State University

\section{FEATURES OF THE REPRESENTATION OF CLASS CONFLICT IN MODERN WESTERN MASS CULTURE ON THE EXAMPLE OF "THE SIMPSONS" TV SERIES}

\begin{abstract}
Summary:
The paper attempts to analyze the peculiarity of the reflection of the class structure and class conflict in the products of modern Western mass culture. The most successful of these cultural products are popular all over the world and influence the attitudes and ideas of people far beyond the boundaries of local communities. Moreover, we can talk about the lack of a comprehensive understanding of exactly how classes in general and class conflict are represented in the products of Western mass culture. As part of the study, using content analysis and discourse analysis, the American animated series "The Simpsons" is analyzed to determine the presence and characteristics of the representation of class conflict. According to the result of the study, it becomes clear that the class polarization in American society, as it is presented in the animated series, is indeed present, how ever, the low level of class consciousness and the absence of institutions that promote the articulation of class interests leads to leads to the fact that class conflict, even with significant potential, is not realized in its current form, is not expressed in direct actions and political acts of both normative and counter-normative order. At the same time, there is a significant transformation of the classes themselves, which are already seriously different from the classical understanding that is associated with the era of industrial capitalism. Not only class boundaries are changing, but also the social conditions and frames that are involved in the formation of class identity in modern Western society.
\end{abstract}

Keywords: social structure, social classes, class conflict, mass culture, popular culture, film and animation research.

Сегодня становится вполне очевидно, что продукты массовой культуры потребляются огромным количеством людей на всем земном шаре. Кроме того, само значение термина «продукт массовой культуры» претерпевает постоянные изменения, призванные описать и ухватить те новые элементы, которые появляются в данной области культурного производства. Мы можем говорить о все возрастающей роли новейших информационных технологий, которые не только выступают мощным ресурсом для распространения продуктов массовой культуры, но и напрямую воздействуют на паттерны как их производства, так и их восприятия. Тиражируемость, широта охвата и интенсивность воздействия делают образы, создаваемые массовой культурой, лучше всего усво- 
яемыми и наиболее стойко сохраняющимися. Таким образом, представление индивида об окружающем мире, которое влияет на его действия и определенным образом детерминирует его поведение, во многом сформировано теми культурными кодами, идеологическими установками и образами, которые усвоены им через продукты массовой культуры. Соответственно, существует непосредственная связь между образами, почерпнутыми из произведений массовой культуры, и теми представлениями и ориентациями, которые складываются у ее потребителей.

При этом можно говорить о том, что существует недостаток комплексного понимания того, каким именно образом различные социальные процессы, в том числе такой, как конфликт между социальными классами, представлены в продуктах массовой культуры. В рамках данного исследования предпринята попытка ответить на этот вопрос с помощью анализа телесериала «The Simpsons» как одного из наиболее заметных и востребованных произведений современной западной массовой культуры.

Методологический аппарат исследования представлен классическим дискурс-анализом. Выбор подобного метода анализа обусловлен целью дать более широкий взгляд на художественное произведение и точнее выделить важные для исследования составляющие. Дискурс-анализ позволяет установить наличие или отсутствие определенных элементов в сюжетном повествовании. Кроме того, данный метод анализа дает возможность сделать заключение о значимости того или иного сюжетного элемента на основе качественных показателей (оценка того, насколько данный элемент влияет на развитие сюжета произведения в целом). Дискурс-анализ необходим для исследований социальных отношений в сюжетном пространстве произведения. Различные действующие лица повествования транслируют определенный дискурс, обусловленный конфигурацией детерминирующих их социальных фактов. Соответственно, понимание того, чем обусловлен тот или иной дискурс и в чем заключаются его особенности, позволит установить, как именно персонажи артикулируют и воспринимают отношения и взаимодействия между социальными классами.

Эмпирическим объектом исследования выступает телесериал «The Simpsons». Выбор в пользу «The Simpsons» обусловлен особой ролью, которую сериал играет в современной американской культуре, значительной аудиторией, продолжительностью (более 30 сезонов), богатством сюжетных линий и большим количеством формальных ффакторов признания важности (награды, премии и т. д.). Значение «The Simpsons» для современной массовой культуры сложно переоценить. Мультсериал известен во всем мире, продолжается уже почти тридцать сезонов подряд и успел собрать крайне внушительную коллекцию наград и номинаций самого разного рода. Пожалуй, сложно на сегодняшний день выделить более культовый мультсериал современности, который имел бы столь широкую аудиторию, состоящую из различных возрастных групп. Сериал транслировался более чем в ста странах мира.

На счету мультсериала десятки престижных наград, а по длительности пребывания на телевидении и количеству серий «The Simpsons» внесен в Книгу рекордов Гиннесса. С уверенностью можно сказать, что «The Simpsons» стал частью истории культуры XX века. Следом за сериалом появился еще целый ряд мультипликационных шоу для взрослых, однако «The Simpsons» до сих пор остается эталоном. В России «The Simpsons» также обрел значительную популярность.

Отметим, что использование мультсериала «The Simpsons» в качестве эмпирического объекта исследования не является инновационным решением. Сериал становился объектом исследовательского внимания со стороны представителей различных академических дисциплин, начиная от семиотики и заканчивая институциональной экономикой [1]. Кроме того, многие исследователи предлагают использовать «The Simpsons» как иллюстративный материал для серьезных академических программ и исследований [2], что в очередной раз подтверждает значимость сериала в глазах научного сообщества и востребованность в академической среде.

Выбор конкретных эпизодов для эмпирического анализа производился путем отбора серий из общего пула на основе присутствия в них классовой проблематики. Из всех эпизодов мультсериала после их просмотра были отобраны те, которые в наибольшей степени согласуются с тематикой исследования.

Обратимся непосредственно к сюжету сериала, чтобы выявить в нем репрезентацию классовой структуры и классового конфликта. Социальную основу спрингфилдского общества (место действия сериала - город Спрингфилд) составляет та прослойка, которая в рамках уже ставшего классическим подхода М. Вебера описывается как средний класс. Если же взглянуть на город с точки зрения марксистской концепции, которая не выделяет средний класс в отдельную категорию (поскольку источником разделения выступают различия в доступе к средствам производства, а не уровень потребления), то большая часть населения Спрингфилда не относится к господствующему классу, поскольку не имеет доступа к контролю социально значимых ресурсов и собственности. Кроме того, большинство жителей остаются наемными работниками и продажа собственного труда, а не доход с капитала, выступают для них основным источником средств к существованию. 
Если говорить в марксистских терминах, то в пространстве Спрингоилда существование господствующего и эксплуатируемого классов прослеживается вполне явно. В наиболее яркой форме классовый конфрликт в Спрингфилде проявляется на АЭС, в связи тем что атомная станция - это главное и крупнейшее промышленное предприятие города, на котором сосредоточено большое количество рабочих, осуществляющих свою деятельность в условиях повышенной опасности. Кроме того, атомной станцией руководит Мистер Бернс, репрезентирующий собой беспринципного капиталиста, стремящегося к наибольшей эксплуатации собственных работников в погоне за прибылью. В одном из эпизодов ему принадлежат следующие слова: «Шиндлер и я похожи как две капли воды. Мы оба владельцы заводов, оба делали снаряды для нацистов, но мои-то взрывались, черт возьми!» [3].

Таким образом, в условиях существования в городе очень крупного промышленного предприятия, которым руководит крайне беспринципный собственник, готовый на все в погоне за прибылью, потенциал классового конфликта в Спрингфилде налицо. Однако до настоящего столкновения, выраженного в форме активной политической борьбы, дело практически никогда не доходит. Одной из причин этого является тот фракт, что сами работники не осознают себя как класс и не проявляют стремления к классовой солидарности среди угнетенных. Наоборот, ощущая социальную дистанцию между собственным положением и положением элит и осознавая несправедливость существующего общественного устройства, они стремятся любой ценой самостоятельно добиться попадания в высшие слои общества, а не поставить вопрос о пересмотре социальной структуры общества в сторону реализации принципов социальной справедливости и равных возможностей для незащищенных слоев населения.

Во многом это связано с тем, что для Соединенных Штатов Америки характерно представление, обычно описываемое термином «американская мечта», которое опирается на убеждение о процветании и успехе благодаря тяжелой работе. Согласно этому представлению, каждый в Америке может достичь успеха. По этой причине американское общество еще острее переживает классовый конфлликт, поскольку многие персонажи стремятся улучшить свое положение, а также подняться по социальной лестнице.

Примером в данной ситуации выступает семья главных героев. Несмотря на то, что семья Симпсонов с точки зрения классической концепции социальной структуры принадлежит к среднему классу (сам Гомер Симпсон определяет социальное положение своей семьи как «верхушку нижнего слоя среднего класса» [4]), они сами часто осознают разрыв между элитами и собственным положением, а иногда даже способны артикулировать собственное положение в марксистских терминах угнетения и эксплуатации. При этом они либо цинично принимают существующие правила игры, либо не видят возможной альтернативы сложившимся условиям.

В одном из эпизодов, когда Лиза Симпсон спорит с албанским школьником, приехавшим на учебу по обмену, о сущности американского общества, Гомер примирительно заявляет: «Пожалуйста, дети, перестаньте драться. Может быть, Лиза права в том, что Америка - страна больших возможностей, и Адил тоже прав насчет шестеренок капитализма, смазанных кровью рабочих» [5].

В другой ситуации он, рассуждая о забастовках, говорит следующую фразу: «Лиза, если тебе не нравится работа, не нужно бастовать. Просто ходишь на работу каждый день и работаешь спустя рукава. Вот это по-американски» [6].

В эпизоде «Scenes from the Class Struggle in Springfield» Мардж Симпсон вместе со своей семьей благодаря дорогому костюму и старому знакомству получает приглашение в закрытый загородный клуб, в который входят самые элитные семейства города. Мардж хочет, чтобы ее семья выглядела идеально и вела себя как можно лучше. Вся семья пытается создать впечатление, что они принадлежат к высшему классу. Это стремление во что бы то ни стало приблизится к элитам доказывает, насколько глубокий разлом пролегает между рядовыми американцами и господствующим классом:

Лиза: «Богатые отличаются от нас с тобой».

Мардж: «Да, они лучше. Социально лучше. И если мы сможем находиться рядом с ними, мы тоже можем быть лучше».

Финал эпизода показывает, что социальное положение - это достаточно прочная структура, которая с трудом поддается изменению: герои возвращаются к своей обычной жизни [7].

Другой причиной, которая способствует сохранению и воспроизводству господствующего класса и приводит к неспособности угнетенных групп к сопротивлению, оказывается отсутствие в Спрингфилде какой-либо политической организации, которая могла бы предложить качественно иной взгляд на мир и организовать сопротивление господствующему порядку. Даже существующие в городе профсоюзы не способны эфффективно и последовательно защищать интересы своих членов и существуют в основном как инструмент в руках собственников предприятий, 
служащий для канализации недовольства рабочих локальными успехами. В эпизоде «Last Exit to Springfield» члены профрсюза атомной энергетики, возглавляемые рабочими Ленни и Карлом, не раздумывая отказываются от «дополнительной страховки» ради бочонка пива для каждого собрания профсоюза [8]. Не лучше обстоит ситуация и с политическими организациями: попытка агитатора коммунистической партии выступить в Спрингфилде на стадионе перед футбольным матчем приводит к тому, что его забрасывают мусором и помидорами [9].

На протяжении всего сериала сохраняется и выделяется тот фракт, что классовая структура в обществе небольшого американского города прослеживается достаточно явно и существует антагонизм между привилегированным меньшинством населения и остальными жителями. Таким образом, складывается ситуация, при которой общество в пространстве Спрингфилда поляризовано и находится в ситуации потенциального классового конфлликта, однако пассивность жителей и отсутствие классовой солидарности, а также слабость организаций, призванных артикулировать требования угнетенных, приводит к тому, что подлинная классовая борьба в активной форме в городе практически отсутствует.

\section{Ссылки и примечания:}

1. Bastian V. The Simpsons and Their World - A Mirror of American Life? // The Simpsons Archive. https://www.simpsonsarchive.com/other/papers/bv.paper.html ; Gray J. Imagining America: The Simpsons go global // Popular Communication. 2007. Vol. 5, no. 2. P. 129-148. doi: 10.1080/15405700701294111 ; Karma W. Representations of Masculinity in The Simpsons // The Simpsons Archive. https://www.simpsonsarchive.com/other/papers/kw.paper.html ; Lorenzo L., Pereira A., Xoubanova M. The Simpsons / Los Simpson // The Translator. 2003. Vol. 9, no. 2. P. 269-291.

2. Hinds H.E., Motz M.F., Nelson A.M.S. Popular Culture Theory and Methodology: A Basic Introduction. Madison, 2004. 412 p. ; Scanlan S.J., Feinberg S.L. The Cartoon Society: Using The Simpsons to Teach and Learn Sociology // Teaching Sociology. 2000. Vol. 28, no. 2. P. 127-139 ; Shepperson A., Tomaselli K.G. Cultural Studies is the Crisis: Culturalism and Dynamic Justice // Cultural Studies Critical Methodologies. 2004. No. 4. P. 257-268. doi: 10.1177/1532708603262784 ; Woodcock P. Gender, politicians and public health: Using the Simpsons to teach politics // European political science. 2008. Vol. 7, no. 2. P. 153-164. doi: 10.1057/eps.2008.5.

3. Эпизод «A Star Is Burns», 1995 - S06 E18.

4. Эпизод «The Springfield Connection», 1995 - S06 E20.

5. Эпизод «The Crepes of Wrath», 1990 - S01 E11.

6. Эпизод «The PTA Disbands», 1995 - S06 E21.

7. Эпизод «Scenes from the Class Struggle in Springfield», 1996 - S07 E14.

8. Эпизод «Last Exit to Springfield», 1993 - S04 E17.

9. Эпизод «Brother from the Same Planet», 1993 - S04 E14.

Редактор, переводчик: Меньшикова Екатерина Олеговна 